\title{
A Design-led FEWW Nexus Approach For Qatar University
}

Theodora Karanisa ${ }^{1}$, Ahmed Ouammi ${ }^{1}$, Helmi Hamdi ${ }^{1}$, Imen Saadaoui ${ }^{1}$, Noora Fetais ${ }^{2}$, Sami Sayadi ${ }^{1}$

${ }^{1}$ Center for Sustainable Development, College of Arts and Sciences, Qatar University, Doha, Qatar

${ }^{2}$ Computer Science and Engineering Department, College of Engineering, Qatar University, Doha, Qatar

\section{Introduction}

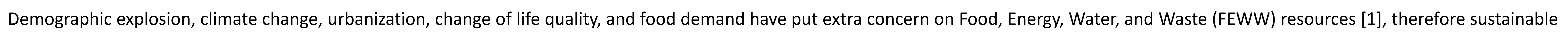

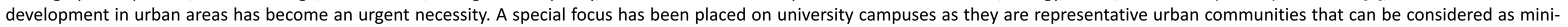

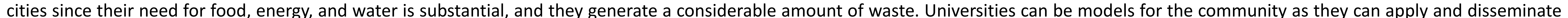
new ideas [2]. Furthermore, small-scale successful applications tested on campus can be later applied to a bigger scale.

\section{Aims and objectives}

The case study of the Qatar University campus as a Doha Living Lab generates ideas and gives solutions to the FEWW Nexus through urban agriculture practices adopted to the climatic conditions of Qatar. The main aim is to produce food sustainably by combining the nature-based systems and the technological systems of the Food-Water-Energy-Waste nexus design to increase food production on the campus while minimizing the use of energy and water, enhancing biodiversity and soil quality. To this end, the focus is on sustainable food waste management and food waste valorization, production systems using hydroponics to mitigate water and soil challenges, greenhouses with minimal energy consumption, and finally, the use of treated sewage effluent (TSE) for landscape irrigation purposes. The Doha Living Lab follows the M-NEX Design method [3], engaging stakeholders and the local community, as shown in Figure 1.

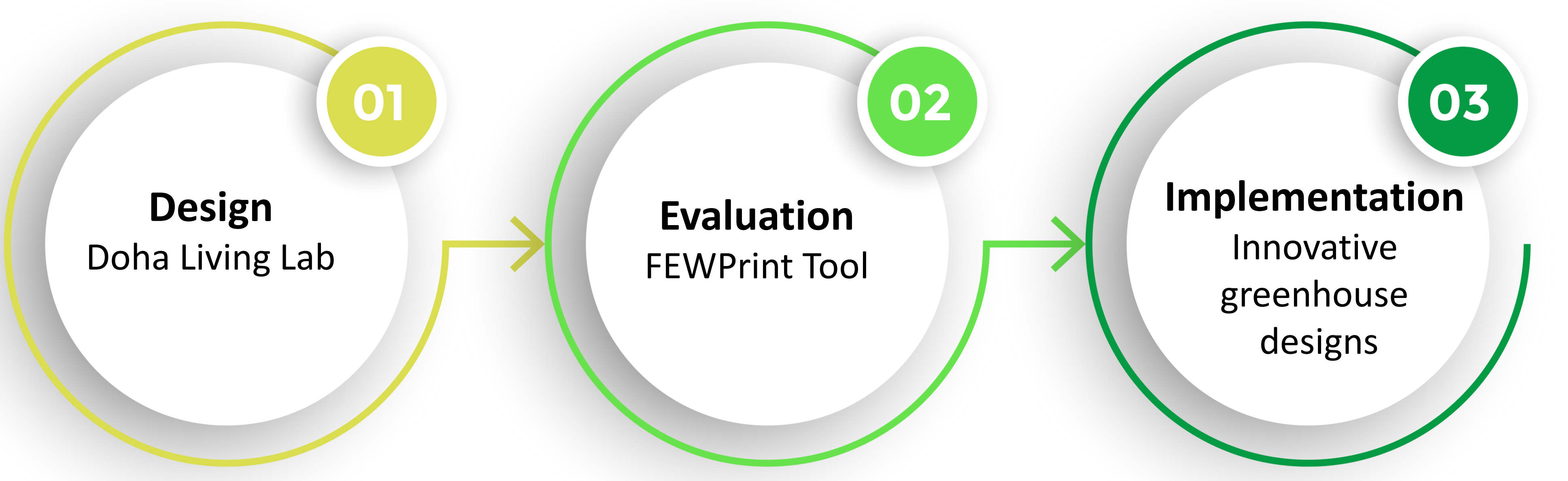

Figure 1. Steps of the M-NEX Design Process [3]

\section{Doha Living Lab Design}

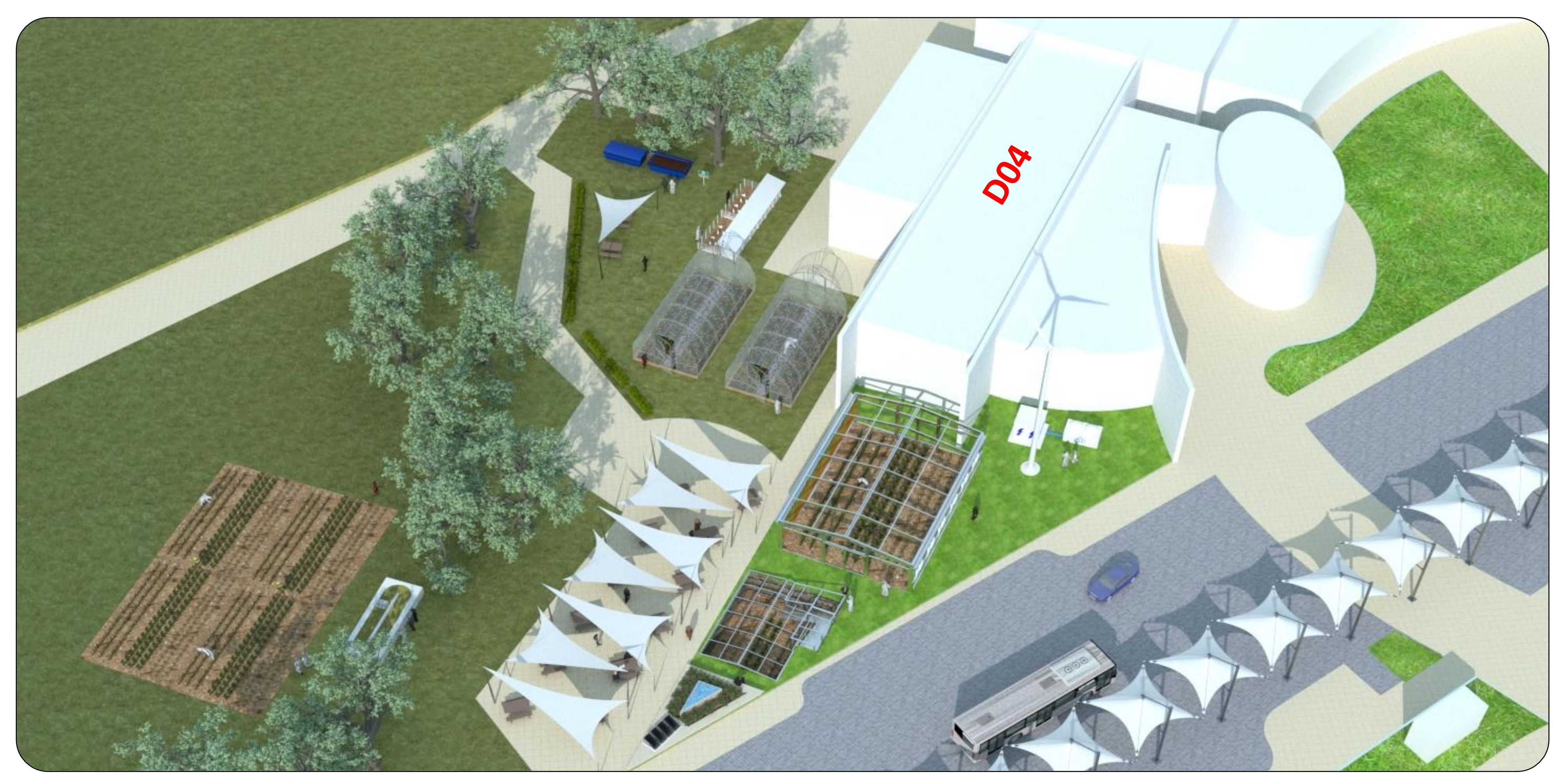

Figure 2. Doha Living Lab design at the QU Campus Main Boulevard, at the edge of the Food Court (D04).

\section{Doha Living Lab Areas}

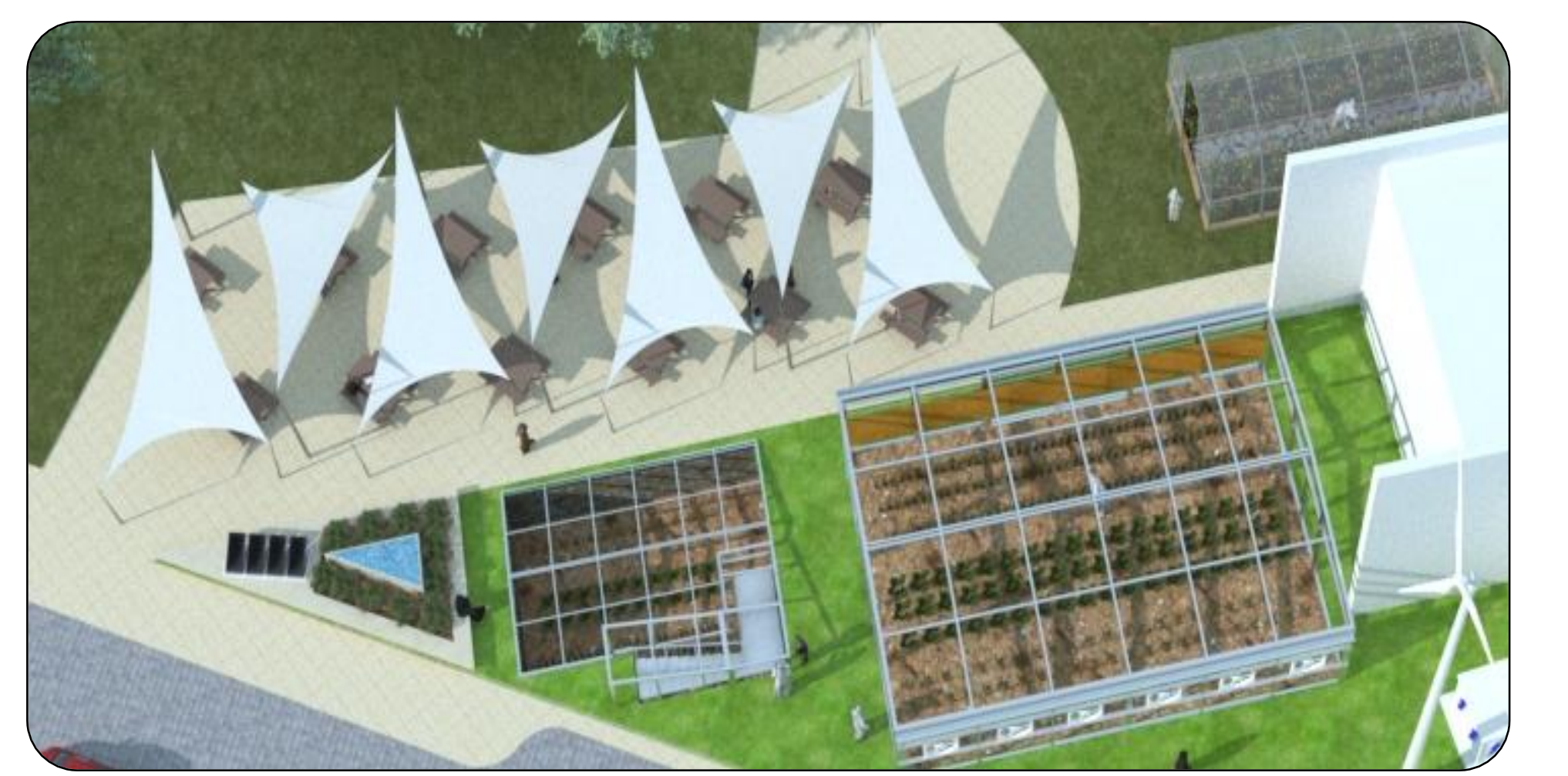

FEW Nexus area

Food: Urban-scale greenhouses and Microalgae raceway pond Energy: PV panels, wind turbine Water: Desalinated groundwater for food production

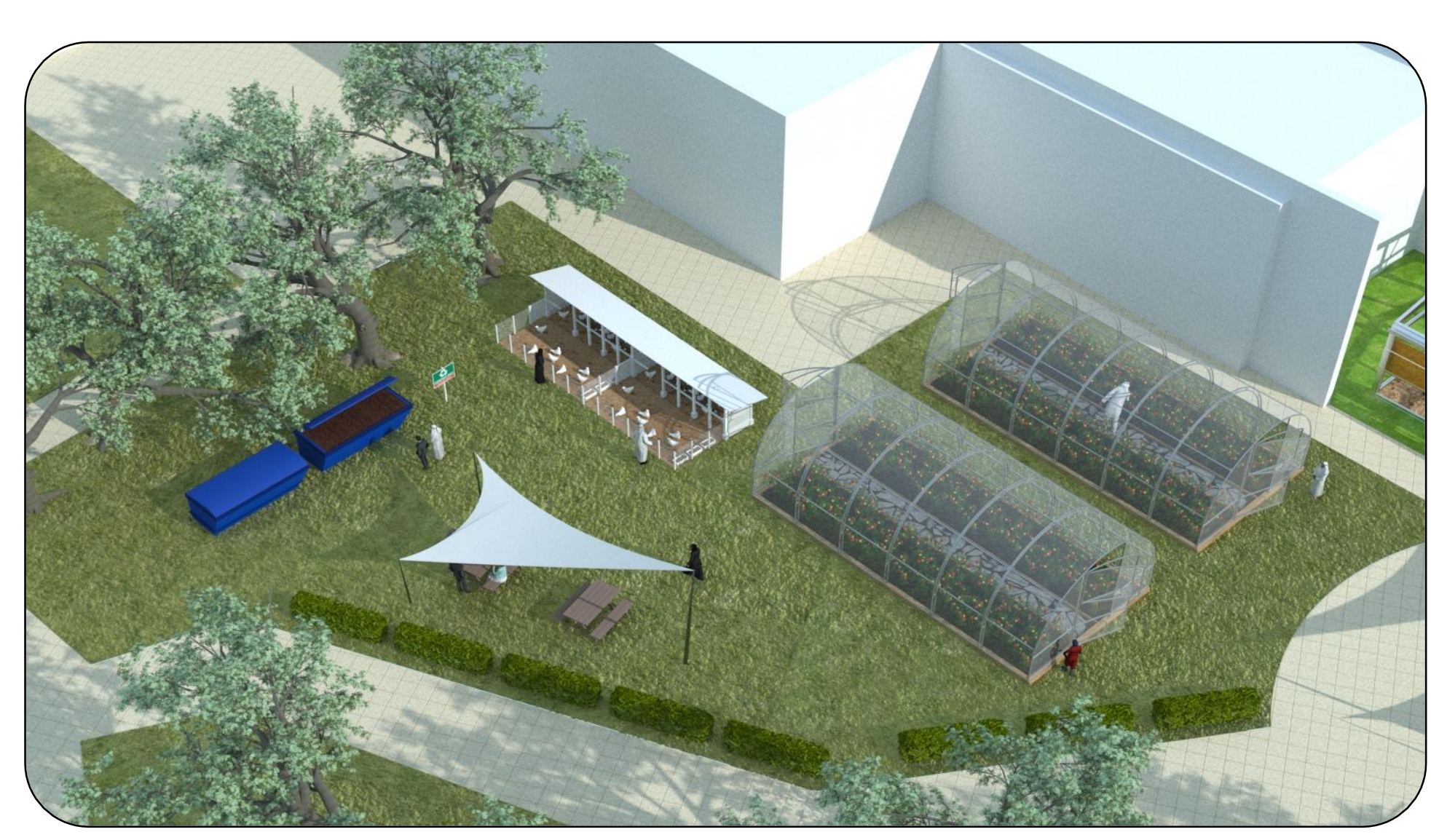

\section{FEWW Nexus area}

Food: Urban-scale net house, poultry farm, open field plots Water: TSE for landscape irrigation purposes

Waste: Food, poultry and green waste composting

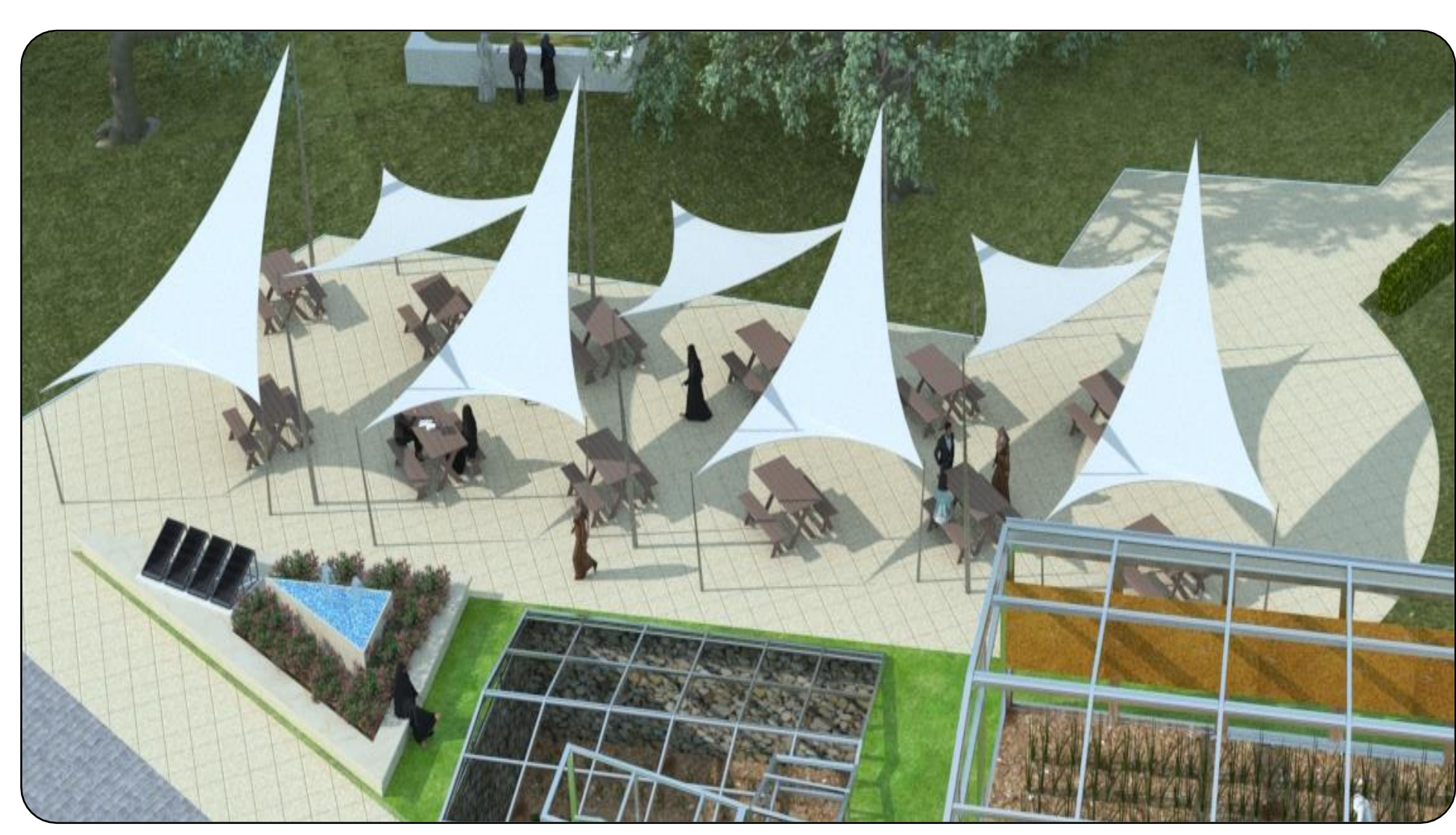

Community area

Meeting point: Green sheltered and shadowed recreational area

Community engagement: Enhanced awareness and participation

\section{Evaluation}

The Doha Living Lab, being an urban farm is assessed as a food system on its own. The FEWprint indicator [4] describes the DLL's performance by calculating the $\mathrm{CO}_{2}$ footprint and explores the impact of local food production on the environment. Two scenarios are presented: the Business-as-usual for imported food and the New scenario if the same food is produced locally. The DLL's local food production (Table 1 ) is reducing the $\mathrm{CO}_{2}$ emissions by 2\% (Table 2).

Table 1: Doha Living Lab food production targets and achieved production.

Target: Satisfy Qatar Dietary Requirements

$\mathrm{N}^{\circ}$ of people in community

100

Consumption

Duration

Food provision (servings)

Vegetables

Legumes

Fruits

Chicken meat

3 days per week

8 months per year

Doha Living Lab

Qatar Dietary Requirements

Eggs

3
1
2
1
1$$
\text { 3-5 }
$$

not specified

not specified

Table 2: Doha Living Lab carbon footprint for BAU Scenario (imported food) and NEW scenario (locally produced food).

Food, Energy and Water carbon footprint

BAU Carbon emissions (imported food)

NEW Carbon emissions (locally produced food) 11 ton/yr.

Food

Energy

Water

Difference

\section{4 ton/yr.}

6 ton/yr.

1 ton/yr. $-2 \%$
Doha Living Lab assumptions - $75 \%$ of energy needs from renewable sources

- $75 \%$ animal feed from biowaste

- Innovative greenhouses with low energy consumption

\section{Implementation}

The Doha Living Lab moves from conceptualization to practice and implements the innovative greenhouse designs on the campus level validating the novel ideas and increasing the community's participation and awareness in the FEWW Nexus.

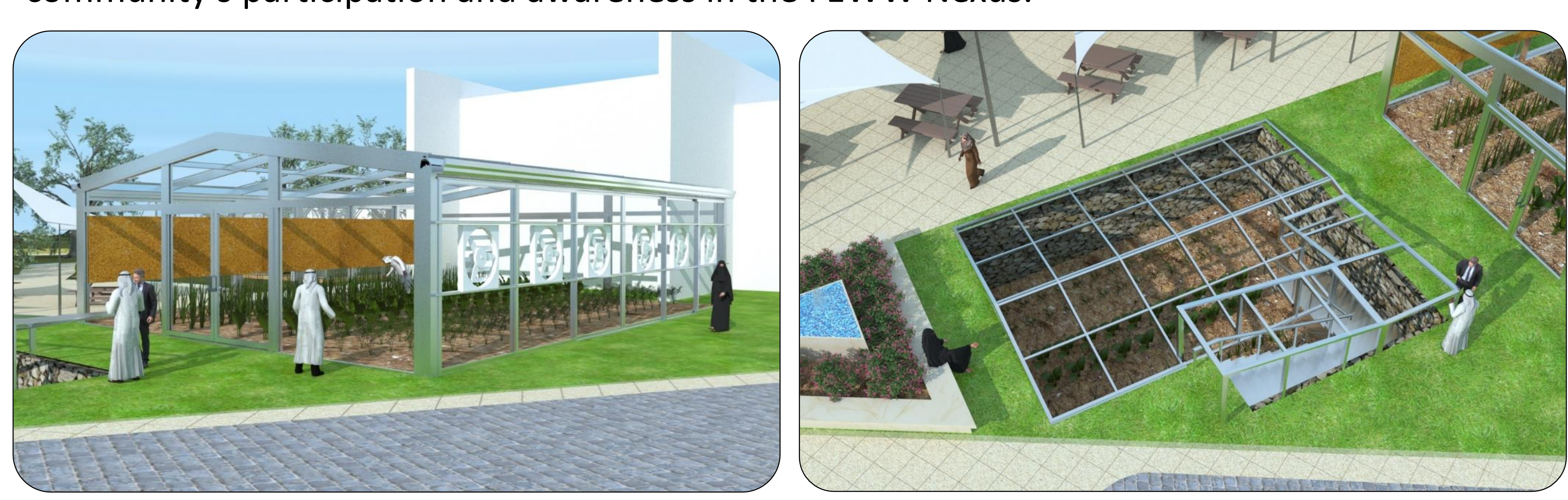

\section{Conclusions and recommendations}

The Doha Living Lab evaluation revealed the following results

$\checkmark$ Energy is the greatest carbon emission contributor

$\checkmark$ Food waste is a valuable resource for composting and animal feed

$\checkmark$ To achieve a sustainable FEWW Nexus in terms of low carbon footprint Use renewable sources of energy

Innovative solutions are needed, such as energy-saving technologies to reduce resource use in food production

Opt for a plant-based diet rather than a meat-based diet to reduce $\mathrm{CO}_{2}$ emissions

\section{References}

1) FAO, IFAD and WFP. (2015). The State of Food Insecurity in the World 2015. Meeting the 2015 international hunger targets: taking stock of uneven progress. Rome, FAO.

2) Malekpour, S.; Caball, R.; Brown, R.; Georges, N.; Jasieniak, J. (2017). Food Energy Water Nexus: Ideas for Monash University Clayton Campus 2017.

3) Yan Wanglin and Roggema Rob (2019). Developing a Design-Led Approach for the FooEnergy-Water Nexus in Cities. Urban Planning, 4:1, 123-138, DOI:10.17645/up.v4i1.1739

4) M-NEX Project WIKI Page.

https://ecogislab.sfc.keio.ac.jp/wiki/index.php?title=Main Page\#Evaluation Tools

5) Al Thani et al. (2018). Adherence to the Qatar dietary guidelines: A cross-sectional study of the gaps, determinants and association with cardiometabolic risk amongst adults. BMC Public Health. 18. 10.1186/s12889-018-5400-2.

\section{Acknowledgements}

This research was made possible by the BFSUG award (BFSUGI01-1120-170005) from the Qatar National Research Fund (QNFR) (a member of Qatar Fo 